\title{
PENGARUH PENERAPAN MODEL DISCOVERY LEARNING DENGAN METODE SYNERGETIC TEACHING TERHADAP HASIL BELAJAR KOGNITIF SISWA
}

\author{
Tanti Hendrayani ${ }^{1}$,Yoyon Sutresna ${ }^{2}$, Adun Rusyana ${ }^{2}$ \\ 1 Universitas Galuh, Jl. R. E. Martadinata No.150, Ciamis, Indonesia \\ 2Universitas Galuh, JI. R. E. Martadinata No.150, Ciamis, Indonesia \\ Email : adunrusyana@gmail.com
}

\begin{abstract}
The purpose of this research was to determine the effect of the application of the Discovery Learning Model with the Synergetic Teaching Method on students' cognitive learning outcomes conducted online. The research method used is Pre-experimental designs with One group pretest posttest design. The research sample was students of class X IPA 3 with purposive sampling technique. The mean pretest score is 34.71 . After the learning process was carried out using the Discovery Learning model with the Synergetic Teaching method, the average posttest score was 82.06. Class X IPA 3, judging from the results of the normality test of the data and the data being normally distributed with the results of 5,307 . Hypothesis testing was carried out using the $Z$ test at a level of $1 \%$, the results of $Z$ test showed that $Z$ count $>Z_{\text {_table, }}$ namely $Z_{\text {count }} 2,45>Z_{\text {_table }} 2.33$. It means that the hypothesis is accepted, so the Discovery Learning model with the Synergetic Teaching method has effect on the students' cognitive learning outcomes. The conclusion was that Discovery Learning model with the Synergetic Teaching method was effective to used for environmental pollution content.
\end{abstract}

Keywords: Discovery Learning Model, Synergetic Teaching Method, Cognitive, Learning Outcomes.

\begin{abstract}
ABSTRAK
Tujuan penelitian ini adalah untuk mengetahui adanya pengaruh dari penerapan Model Discovery Learning dengan Metode Synergetic Teaching terhadap hasil belajar kognitif siswa yang dilakukan secara online. Metode penelitian yang dilakukan adalah Pre-experimental designs dengan One group pretest posttest design. Sampel penelitian adalah siswa kelas X IPA 3 dengan teknik purposive sampling. Rerata skor pretest yaitu 34,71. Setelah dilakukan proses pembelajaran dengan menggunakan model Discovery Learning dengan metode Synergetic Teaching diperoleh rerata skor posttest 82,06. Kelas X IPA 3, dilihat dari hasil uji normalitas data dan data tersebut berdistribusi normal dengan hasil 5,307. Uji Hipotesis dilakukan dengan menggunakan uji Z pada taraf $1 \%$, menunjukkan hasil $Z_{\text {hitung }}>Z_{\text {tabel }}$ yaitu $Z_{\text {hitung }} 2,45>Z_{\text {tabel }} 2,33$ artinya pembelajaran dengan menggunakan model Discovery Learning dengan metode Synergetic Teaching berpengaruh terhadap hasil belajar kognitif siswa. Kesimpulan bahwa model Discovery Learning dengan metode Synergetic Teaching efektif digunakan pada materi Pencemaran lingkungan.
\end{abstract}

Kata Kunci: Model Discovery Learning, Metode Synergetic Teaching, Hasil Belajar Kognitif.

Cara sitasi: Hendrayani, T., Sutresna, Y. \& Rusyana, A. (2021). Pengaruh Penerapan Model Discovery Learning Dengan Metode Synergetic Teaching Terhadap Hasil Belajar Kognitif Siswa. Bioed: Jurnal Pendidikan Biologi, 9 (2), 19-24. 


\section{PENDAHULUAN}

Pendidikan merupakan suatu usaha sadar dan terencana untuk mewujudkan suatu proses atau kegiatan pembelajaran bagi peserta didik yang secara aktif mengembangkan potensi yang dimilikinya seperti kecerdasan, keterampilan, sikap spiritual dan sebagainya. Sebagai seorang pendidik guru tentunya dituntut agar lebih bisa mengembangkan model dan metode pembelajaran untuk meningkatkan prestasi belajar siswanya. Belajar merupakan suatu proses yang dilakukan individu untuk memperoleh perubahan tingkah laku yang dilakukan secara sengaja untuk mendapatkan perubahan yang lebih baik (Mulyono, 2017:39). Sujiwo dan A'yun (2018:93) mengemukakan bahwa pembelajaran pada umumya harus berjalan dengan siswa yang berperan aktif dan ikut serta dalam kegiatan belajar mengajar.

Pendidikan bertujuan untuk mengembangkan potensi peserta didik agar menjadi manusia yang beriman, bertaqwa kepada Tuhan Yang Maha Esa, berakhlak mulia, sehat, berilmu, cakap, kreatif, mandiri dan menjadi warga negara yang demokratis serta dapat bertanggung jawab yang merupakan suatu karakter Pancasila yang menjadi tujuan Pendidikan Nasional (Anonim, 2015). Dalam suatu tujuan pembelajaran akan tercapai apabila siswa ikut serta dan terlibat secara aktif untuk mencapai kegiatan pembelajaran yang ideal. Keaktifan siswa tersebut tidak lepas dari guru yang membimbing selama proses pengajaran karena kualitas pendidikan yang bagus tersebut akan membawa siswa untuk lebih meningkatkan hasil belajar serta prestasi belajarnya untuk menjadi lebih baik. Dalam suatu proses pembelajaran, siswa tidak hanya sebagai subjek akan tetapi sebagai objek juga untuk tercapainya hasil belajar.

Perkembangan teknologi informasi pada era sekarang sangat berkembang pesat. Hal tersebut dapat dimanfaatkan oleh guru pada situasi sekarang karena adanya pandemik Covid-19 yang mengharuskan siswa belajar di rumah karena sedang menerapkan social distancing. Pembelajaran online merupakan pembelajaran yang dapat mempertemukan siswa dengan gurunya untuk melaksanakan pembelajaran dengan bantuan internet (Kuntarto, E 2017). Banyaknya aplikasi yang mendukung untuk melakukan pembelajaran daring seperti Zoom cloud meeting, Google Classroom, edmodo, Schoology, dan lain-lain. Hak tersebut tidak akan menutup kemungkinan untuk tetap belajar selama masa pandemik berlangsung.

Keberhasilan suatu proses pembelajaran dan hasil belajar sangat ditentukan oleh beberapa faktor di antaranya adalah siswa dan guru. Kegiatan pembelajaran yang dilaksanakan oleh guru diharapkan dapat membawa perubahan siswa ke arah yang lebih positif yang memberikan peran aktif kepada siswanya. Salah satu untuk menciptakan suatu proses pembelajaran yang menyenangkan adalah dengan cara guru dapat menggunakan model-model pembelajaran yang relevan dan mendukung tercapainya tujuan pembelajaran. Dalam hal ini, model pembelajaran yang dianggap sesuai adalah model pembelajaran berbasis penemuan, arti dan hubungan, melalui proses intuitif untuk akhirnya sampai kepada kesimpulan yang merupakan model Discovery Learning (DL). Model pembelajaran Discovery Learning ini diartikan sebagai proses pembelajaran yang berbasis penemuan suatu konsep yang membuat siswa tersebut aktif terlibat dalam pembalajaran. Dalam penemuan konsep tersebut siswa melakukan pengamatan, menggolongkan, membuat dugaan, menjelaskan, menarik kesimpulan dan sebagainya yang bertujuan untuk menemukan suatu konsep tersebut (Handoko, et al., 2016:145).

Sari, et al., (2016:1404) mengatakan bahwa model pembelajaran Discovery Learning merupakan model pembelajaran yang berbasis penemuan, pada model ini siswa tidak diberikan informasi secara langsung melainkan siswa dituntut untuk mengorganisasikan pemahaman mengenai informasi tersebut secara mandiri. Model pembelajaran ini menitikberatkan pada kemampuan siswa dalam memecahkan suatu permasalahan dalam proses pembelajaran melalui rasa ingin tahu siswa menemukan hal penting dalam materi pembelajarannya.

Metode Synergetic Teaching merupakan suatu metode pembelajaran yang menggabungkan dua perlakuan yang berbeda. Metode Synergetic Teaching ini merupakan metode pembelajaran active learning yang memberikan peran aktif kepada siswanya untuk saling berbagi pengalaman 
belajar dan membandingkan dari catatan hasil belajar selama pembelajaran (Sujiwo dan A'yun, 2018:94).

Ciri-ciri metode pembelajaran synergetic teaching yaitu : (1) berpusat pada siswa (student centered), (2) proses pembelajaran mengutamakan pemberian pengalaman langsung, dan (3) pemisah antar bidang studi tidak terlihat jelas. Berdasarkan ciri-ciri tersebut menunjukan bahwa metode synergetic teaching ini pembelajaran berpusat pada siswa yang sesuai dengan kurikulum 2013 yang menuntut siswanya agar berperan aktif selama proses pembelajaran berlangsung (Anonim, 2015). Metode Synergetic Teaching ini memberikan pengalaman pada peserta didik untuk mendapatkan pengalaman belajar yang berbeda dalam mempelajari materi yang sama.

Hasil belajar merupakan suatu objek penilaian yang dapat dibagi menjadi tiga ranah, yaitu ranah keterampilan dan kebiasaan (psikomotor), ranah yang berkenaan dengan hasil belajar intelektual dan sikap (afektif) dan ranah yang berkenaan dengan hasil belajar serta pengetahuan siswa dalam pembelajaran (kognitif) Sudjana (2016:34). Kategori dari proses kognitif yang paling umum dikemukakan adalah tujuan, mengingat, memahami, menerapkan, menganalisis, mengevaluasi dan menciptakan (Kuswana, 2014:115)

Hasil belajar tersebut merupakan suatu hasil yang telah dicapai seorang siswa setelah mengalami proses belajar. Hasil belajar dikatakan tuntas apabila telah memenuhi kriteria penilaian maksimum yang telah ditetapkan oleh guru mata pelajaran. Menurut Taksonomi Bloom yang telah direvisi oleh Anderson dan Krathwohl (2001, dalam Gunawan \& Palupi, 2008) indikator dari hasil belajar kognitif diantaranya menciptakan, memahami, menerapkan, menganalisis dan mengsintesis, mengevaluasi dan menciptakan.

Penelitian-penelitian proses pembelajaran yang menggunakan model Discovery learning sudah banyak dilakukan, tetapi umumnya tidak menggunakan metode Synergetic Teaching, oleh karena itu perlu diketahui pengaruh mengintegrasikan metode ini pada Discovery Learning.Tujuan penelitian ini untuk mengetahui pengaruh penerapan model Discovery Learning dengan metode Synergetic Teaching terhadap hasil belajar kognitif siswa pada materi Pencemaran lingkungan.

\section{METODE PENELITIAN}

Waktu penelitian terhitung dari mulai bulan januari sampai dengan juni 2020. Penelitian dilakukan di SMA N 3 Ciamis. Metode dalam penelitian ini adalah metode pre-experimental design Sugiyono,2014:74) dengan desain penelitian One-group pretest-posttest design mengartikan bahwa desain ini tidak terdapat kelas kontrol dan sampel tidak dipilih secara random.

Tabel 1. Rancangan eksperimen

\begin{tabular}{lrrc}
\hline Kelompok & Pretest & Perlakuan & Posttest \\
\hline KE & $\mathrm{O}_{1}$ & $\mathrm{X}$ & $\mathrm{O}_{2}$
\end{tabular}

Keterangan:

KE: kelompok eksperimen

$X$ : perlakuan dengan perlakuan menggunakan model Discovery Learning dengan metode

Synergetic Teaching

$\mathrm{O}_{1}$ : pemberian pretest $\mathrm{O}_{2}$ :

pemberian posttest

Populasi penelitian ini adalah siswa kelas X IPA di SMA N 3 Ciamis pada semester genap tahun ajaran 2019/2020. Anggota populasi terdiri dari 3 kelas dengan jumlah total 95 siswa. Teknik sampling yang digunakan dalam penelitian ini dipilih secara purposive sampling karena penentuan sampel dilakukan dengan pertimbangan hasil observasi bahwa kelas tersebut memiliki tingkat hasil belajar kognitif yang relatif lebih rendah dibandingkan dengan kelas lain. Dalam penelitian ini yang dijadikan sebagai sampel adalah kelas X IPA 3.

Variabel penelitian ini terdiri atas dua variabel yaitu variabel bebas dan variabel terikat. 
Variabel bebas (Independen) merupakan variabel yang mempengaruhi timbulnya variabel terikat. Variabel bebas yang digunakan dalam penelitian ini adalah Model Discovery Learning dengan menggunakan metode Synergetic Teaching. Variabel terikat (Dependen) merupakan variabel yang dipengaruhi atau yang menjadi akibat adanya variabel bebas. Variabel terikat dalam penelitian ini adalah Peningkatan pada hasil belajar kognitif siswa setelah menggunakan Model Discovery Learning dengan menggunakan metode Synergetic Teaching.

Instrumen penelitian ini menggunakan soal pilihan ganda sebanyak 20 soal pada materi pencemaran limgkungan dan diberikan pada saat sebelum dan sesudah diberi perlakuan. Dilakukannya pengujian hipotesis dengan dengan menggunakan uji Z. Untuk menguji hipotesis digunakan uji $Z$ pada taraf signifikan $\alpha=1 \%$ dengan kriteria hipotesis diterima apabila nilai $Z_{\text {hitung }}>$ $Z_{\text {daftar }}$ (Nurgana, 1985:10).

\section{HASIL DAN PEMBAHASAN}

Penelitian ini dilakukan di SMA Negeri 3 Ciamis secara online karena situasi adanya pandemik Covid-19 yang mengharuskan belajar di rumah, penelitian ini dilakukan pada kelas X IPA 3 pada tanggal 20 April 2020 dengan menggunakan aplikasi Zoom cloud meeting. Berdasarkan kegiatan pembelajaran yang dilakukan pada materi Pencemaran Lingkungan yang menggunakan model Discovery Learning dengan metode Synergetic Teaching, diperoleh data hasil penelitian ini meliputi nilai pre-test dan post-test. Pengolahan data dilakukan pada data hasil dari pre-test dan post-test yang . Hasil analisis data disajikan pada tabel 1. Berikut ini adalah rata-rata pre test, post test dan N-gain.

Tabel 1. Perolehan Data Hasil Pree-test dan Post-test

\begin{tabular}{ccccc}
\hline Nilai & Pree-test & Post-test & N-Gain & \% N-Gain \\
\hline Data Terkecil & 20 & 70 & 0,29 & 29 \\
Data Terbesar & 65 & 95 & 0,93 & 93 \\
Rata-Rata & 34,71 & 82,06 & 0,70 & 70,31
\end{tabular}

Pada tabel 1 , diketahui bahwa rata-rata hasil pre-test sebesar 34,71 , rata-rata hasil posttest sebesar 82,06 dan rata-rata N-Gain sebesar 0,70. Sedangkan untuk nilai pree-test terkecil 20 dan terbesar 65, untuk nila post- test terkecil 70 dan ter erbesar 95. I N-Gain terkecil 0,29 dan terbesar 0,93 . Selanjutnya dilakukan uji normalitas, hasil analisis menunjukkan data berdistribusi normal disajikan pada tabel 2.

Tabel 2. Hasil Perhitungan Uji Normalitas

\begin{tabular}{|c|c|c|}
\hline No & Langkah Pengujian & Hasil \\
\hline 1. & Normalitas Distribusi & \\
\hline & - $X^{2}$ Hitung & 5,307 \\
\hline & $\begin{array}{l}\text { - } X^{2}(0,99)(2) \\
\text { - } \quad \text { kesimpulan }\end{array}$ & $\begin{array}{l}9,21 \\
X^{2} \text { Hitung }<X^{2}(0,99)(2) \text { maka sampel berdistribusi normal }\end{array}$ \\
\hline
\end{tabular}

Berdasarkan hasil uji normalitas diketahui bahwa $X^{2}$ Hitung sebesar 5,307 lebih kecil dibandingkan dengan $X^{2}$ Daftar sebesar 9,21 . Hal ini berarti sampel berdistribusi normal. Selanjutnya dilakukan Uji Hipotesis dengan menggunakan Uji Z untuk mengetahui apakah hipotesis diterima 
atau hipotesis ditolak. Berdasarkan hasil perhitungan dari uji $Z$ maka diperoleh nilai $Z$ hitung sebesar 2,45 sedangkan $Z$ tabel sebesar 2,33. Dengan demikian $Z$ hitung lebih besar dari $Z$ tabel, maka hipotesis diterima, artinya penerapan model Discovery Learning dengan metode Synergetic Teaching berpengaruh terhadap hasil belajar kognitif pada materi pencemaran lingkungan. Nilai rata-rata $\mathrm{N}$-Gain sebesar 0,70 dan termasuk dalam kriteria sedang.

Berdasarkan hasil analisis data menunjukkan model Discovery Learning dengan metode Synergetic Teaching berpengaruh terhadap hasil belajar kognitif dengan peningkatan sedang . Hal ini terjadi karena siswa dapat memahami konsep yang diajarkan dengan menemukan pengetahuan yang baru yang diperoleh melalui penerapan model Discovery Learning. Dari hasil penelitian ini diperoleh nilai rata-rata pre-test 34,71 dan nilai rata-rata post-test 82,06 . Nilai tersebut apabila dibandingkan dengan nilai Kriteria Ketuntasan Minimum (KKM) sebesar 60, maka dapat dikatakan memenuhi nilai kriteria minimal, yang artinya penggunaan model Discovery Learning dengan metode Synergetic Teaching ini dinyatakan mampu meningkatkan hasil belajar kognitif siswa. Hal ini diperkuat dari hasil uji hipotesis, adanya pengaruh yang signifikan dari model Discovery Learning dengan metode Synergetic Teaching terhadap hasil belajar kognitif siswa.Beberapa alasan peningkatah hasil belajar ini antara lain para siswa baru menggunakan model discovery learning ini, sehingga mereka memiliki ketertarikan dan motivasi yang baik untuk belajar. Pembelajaran ini berpusat pada siswa ,sehingga siswa memiliki kebebasan untuk beraktifitas dalam melakukan eksplorasi, mengumpulkan data, menganalisis dan mengomunikasikannya yang memberdayakan siswa dapat menemukan sendiri konsep-konsep dari materi yang dikaji. Hal ini diperkuat dengan hasil penelitian yang dilakukan oleh Sari, et al (2016) bahwa pembelajaran dengan menggunakan model Discovery Learning berpengaruh terhadap hasil belajar kognitif, afektif serta psikomotor pada materi sel di SMA. Penelitian lain dilakukan juga pada mata pelajaran lain oleh Sujiwo et al (2018) yang meneliti efektifitas dari metode Synergetic Teaching pada pembelajaran matematika. Hasil analisis tersebut menunjukan bahwa pembelajaran dengan menggunakan metode Synergetic Teaching efektif ditinjau dari hasil belajar dan aktivitas selama pembelajaran.

Pada penelitian ini, pembelajaran ini dilakukan secara online karena situasi pandemi Covid19, sehingga ditemukan beberapa kelemahan antara lain masih ada beberapa siswa yang kurang aktif selama proses pembelajaran, hal ini terjadi salah satu penyebabnya kualitas dari jaringan internet siswa yang lemah, tetapi secara umum kegiatan pembelajaran yang telah dilakukan oleh peneliti ini cukup memuaskan, akan tetapi peneliti menduga model pembelajaran ini akan lebih baik jika dilakukan secara langsung tatap muka di kelas dibandingkan dengan pelaksanaan pembelajaran online.

\section{KESIMPULAN}

Penerapan model Discovery Learning dengan metode Synergetic Teaching berpengaruh terhadap hasil belajar kognitif siswa, terdapat peningkatan hasil belajar dengan kriteria sedang, sehingga model Discovery Learning dengan metode Synergetic Teaching efektif digunakan pada materi Pencemaran lingkungan.

\section{DAFTAR PUSTAKA}

Arikunto, S. (2018). Dasar-dasar Evaluasi Pendidikan Edisi 2. Jakarta. Bumi Aksara

Cahyo, A ,N. (2013). Panduan Aplikasi Teori-teori Belajar Mengajar Teraktual Dan Terpopuler. Jogjakarta:Diva Press (Anggota IKAPI)

Dewa, E. Et al. (2020). "Pengaruh Pembelajaran Daring Berbantuan Laboratorium Virtual Terhadap Minat dan Hasil Belajar Kognitif Siswa". Jurnal Riset Teknologi dan Inovasi Pendidikan (JARTIKA). 3(2):351-359.

Gunawan, I dan Palupi, A, R. (2016). "Taksonomi Bloom - Revisi Ranah Kognitif: Kerangka Landasan Untuk Pembelajaran, Pengajaran, Dan Penilaian". Program Studi PGSD FIP IKIP PGRI Madiun. (Jurnal Peneltian)

Hanafiah, N. dan Suhana, C. (2012). Konsep Strategi Pembelajaran. 
Bandung:Refika Aditama.

Handoko, A. et al. (2016). "Pengembangan Modul Biologi Berbasis Discovery Learning (Part Of Inquiry Spectrum Learning-Wenning) Pada Materi Bioteknologi Kelas XII IPA Di SMA Negeri 1 Magelang Tahun Ajaran 2014/2015". Jurnal Inkuiri, 5(3):144-154.

Istiana, G, A. et al. (2015). "Penerapan Model Pembelajara Discovery Learning untuk Meningkatkan Aktivitas dan Prestasi Belajar Pokok Bahasa Larutan Penyangga Pada Siswa Kelas IX IPA Semester II SMA Negeri 1 Ngemplak Tahun Pelajaran 2013/2014." Jurnal Pendidikan Kimia, $4(2): 65-73$

Kemendikbud. (2015). Siswa Berkarakter Pancasila Menjadi Tujuan Pendidikan Nasional. [Online]. Tersedia: https://www.kemedikbud.go.id/main/blog/2015/05/siswa-berkarakter- pancasila-menjaditujuan-pendidikan-nasional-4153-4153-4153

Kuswana, W. (2014). Taksonomi Kognitif Perkembangan Ragam Berfikir. Bandung: PT Remaja Rosdakarya

Mulyono, N. (2017). Kurikulum dan Pembelajaran. Bandung:Rizqi Press.

Noor, E, M. Et al. (2017). "Penggunaan E-Learning dalam Pembelajaran Berbasis Proyek di SMA Negeri 1 Jepara". Jurnal Prodi Kurikulum dan Teknologi Pembelajaran, 6(1):17-26.

Priansa, D. J. (2017). Pengembangan Strategi Dan Model Pembelajaran. Bandung. CV Pustaka Setia.

Rahmawati. (2017). "Penerapan Pembelajaran Blanded pada Mata Kuliah Fisiologi Tumbuhan". Jurnal Pendidikan Biologi. 6(2):91-94.

Sadikin, A dan Hamidah, A. (2020). "Pembelajaran Daring di Tengah wabah COVID-19". Jurnal Program Studi Pendidikan Biologi FKIP Unoversitas Jambi. 6(02):214-224.

Sari, E, N. Et al. (2016). "Pengaruh Model Pembelajaran Discovery Learning dengan Mind Mapping Terhadap Hasil Belajar Siswa Pada Materi Sel Di SMA". Jurnal Pendidikan Matematika dan IImu Pengetahuan Alam. 5(3):1403-1407.

Silberman, M, L. (2016). Active Learning 101 Cara Belajar Siswa Aktif Edisi Revisi. Bandung. Nuansa Cendikia.

Simbolon, E, R dan Tapilouw, F, S. (2015). "Pengaruh Pembelajaran Berbasis Masalah dan Pembelajaran Kontekstual Terhadap Berfikir Kritis Siswa SMP". Program Studi Pendidikan IPA, SPs Universitas Pendidikan Indonesia, Bandung, Indonesia. VII(1):97-104.

Sismulyasih, N. (2015). "Peningkatan Menulis Manuskrip Jurnal IImiah Menggunakan Strategi Synergetic Teaching pada Mahasiswa PGSD UNNES". Jurnal Pendidikan Guru Sekolah Dasar. 4(1):64-70.

Sudjana, N. (2016). Penilaian Hasil Belajar Mengajar. Bandung. PT. Remaja Rosdakarya.

Sudjana. (2005). Metode Statiska. Bandung. PT Tarsito Sugiyono, (2015). Statiska Untuk Penelitian. Bandung:Alfabeta.

Sugiyono (2017). Metode Penelitian Pendidikan Pendekatan Kuantitatif, Kualitatif, dan R\&D. Bandung:Alfabeta.

Surya, M. (2004). Psikologi Pembelajaran dan Pengajaran. Bandung:Pustaka Bani Quraisy.

Sujiwo, C, A, D. Dan A'yun, Q. (2018). "Efektifitas Synergetic Teaching pada Pembelajaran Matematika". Jurnal Pendidikan Matematika. 1(2):91-100.

Syarifah, S. (2016). Strategi Belajar Mengajar Metode Synergetic Teaching. [Online]. Tersedia: http://sitisyarifah94.blogspot.com/2016/05/strategi-belajar-mengajar- metode.html?m-1 